\title{
Study of outcome of obstetric emergencies admitted to intensive care unit
}

\author{
B. Rao Bahadur ${ }^{1 *}$, Prabhadevi Kodey ${ }^{1}$, Jeevitha Tanniru ${ }^{1}$, Suhasini Tirumala ${ }^{2}$
}

\begin{abstract}
${ }^{1}$ Department of Obstetrics and Gynecology, ${ }^{2}$ Department of Critical Care Medicine, NRI Medical College and General Hospital, Chinakakani, Mangalagiri Mandal, Guntur District, Andhra Pradesh, India
\end{abstract}

Received: 09 May 2018

Accepted: 31 May 2018

\section{*Correspondence:}

Dr. B. Rao Bahadur,

E-mail: drraobahadur@yahoo.com

Copyright: (c) the author(s), publisher and licensee Medip Academy. This is an open-access article distributed under the terms of the Creative Commons Attribution Non-Commercial License, which permits unrestricted non-commercial use, distribution, and reproduction in any medium, provided the original work is properly cited.

\begin{abstract}
Background: Critically ill obstetric patients pose challenges to the intensive care unit team due to their altered physiology as well as due the presence of the foetus and safety of both the mother and the foetus is of paramount importance.

Methods: All antenatal and postnatal cases within 42days of delivery requiring ICU admission from October 2014 to September 2016. Detailed history taken and outcome noted. Results were subjected to statistical evaluation using SSP software.

Results: $(n=75)$ : obstetric reasons $(n=51,68 \%)$ of which $21(28 \%)$ had PPH and $17(22.6)$ had hypertensive disorders of pregnancy. Non-obstetric reasons $(n=24,32 \%)$ of which $7(9.3 \%)$ cases had jaundice and $4(5.3 \%)$ had malaria. Mechanical ventilation was needed in the majority of cases $(n=44,58.7 \%)$ followed by inotropic support ( $n=30$, $40 \%)$.Maternal mortality was $16 \%$. Mortality was higher $(n=8,66.6 \%)$ among patients admitted for obstetric reasons as opposed to non-obstetric indications $(n=4,33.3 \%)$.

Conclusions: Early detection and prompt referral to the tertiary centre with intensive care facilities should be promoted among the medical fraternity to reduce the incidence of ICU admissions and maternal mortality. All residents of obstetrics and gynaecology should have short mandatory training phase in critical care. Multicentre randomised studies are required for formulating evidence-based national guidelines.
\end{abstract}

Keywords: Blood products, ICU, Maternal mortality, PPH, PIH

\section{INTRODUCTION}

Critically ill obstetric patients pose challenges to the intensive care unit team due to their altered physiology as well as due the presence of the foetus and safety of both the mother and the foetus is of paramount importance. The incidence of pregnant women admitted to intensive care unit (ICU) in developed countries is 2 to 4 per 1,000 deliveries as compared with 2 to 13.5 per 1,000 deliveries in developing countries. ${ }^{1}$
Although obstetric patients form a significant proportion of ICU admission in developing countries, there are only a few studies reporting on critical illness during pregnancy.

Richa et al identified serious lack of knowledge on obstetric care and called for increasing reporting of data. ${ }^{2}$

According to the World Health Organization (WHO), "there is a story behind every maternal death or life- 
threatening complication, and understanding the lessons to be learned can help to avoid such outcomes". 3

A better knowledge of the spectrum, characteristics and outcomes of the diseases involving this group of patients is the first step towards achieving prevention and the current study is done to supplement the present knowledge on obstetric emergencies requiring ICU care.

The present study is done to evaluate maternal and foetal outcome in obstetric emergencies admitted to ICU and review the characteristics of obstetric, non-obstetric causes, treatment and interventions done in ICU.

\section{METHODS}

This is a descriptive observational study conducted at NRI Medical College and General Hospital located at Chinakakani, Guntur District, Andhra Pradesh from October 2014 to September 2016. 75 cases were included in this study period. Data on demographics, obstetrics history, treatments given in ICU, maternal and foetal outcome were collected.

\section{Inclusion criteria}

All antenatal irrespective of the period of gestation and postnatal women within 42 days of delivery requiring ICU admission for obstetric, non-obstetric reasons, irrespective of age, parity, mode of delivery, and comorbid conditions.

\section{Exclusion criteria}

Patients requiring ICU admission after 42 days of delivery.

Results were subjected to statistical analysis using SPSS software version 22 and conclusions drawn.

\section{RESULTS}

During the study period of 2 years, a total number of 75 obstetric patients were admitted to ICU. This constituted $1.29 \%$ of total deliveries and $1.1 \%$ of total ICU admissions during study period.

Most of the patients admitted to the ICU were young with

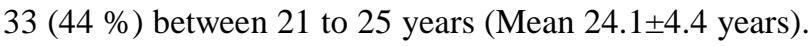
$48(64 \%)$ were from rural areas and $27(36 \%)$ from urban areas. Majority $58(77 \%)$ of them were registered / booked at other hospitals, referred to our hospital because of complications. $41(54.66 \%)$ were primigravida's and $20(26.7 \%)$ were second gravida. Majority were in third trimester $49(65.3 \%)$ and postpartum period $16(21.3 \%)$ rest were in I and II trimesters (mean gestational age $31.9 \pm 7.1$ weeks). 34 (45.3\%) showed pallor, 32(42.6\%) pedal edema and $15(20 \%)$ had icterus at admission. Hypotension was noted in $10(13.3 \%)$ and hypertension in $23(30.7 \%)$.
$55(73.3 \%)$ were admitted to ICU in the postpartum period and $20(26 \%)$ were admitted in antenatal period.

Table 1: Indication for ICU admission.

\begin{tabular}{|c|c|c|}
\hline $\begin{array}{l}\text { Indication for ICU } \\
\text { admission }\end{array}$ & $\begin{array}{l}\text { No. of } \\
\text { patients }\end{array}$ & $\begin{array}{l}\text { Percentage } \\
(\%)\end{array}$ \\
\hline Obstetric causes & 51 & 67.9 \\
\hline Obstetric Haemorrhage & 29 & 38.6 \\
\hline $\mathrm{PPH}$ & 21 & 28 \\
\hline APH-abruption & 2 & 2.6 \\
\hline APH-placenta praevia & 2 & 2.6 \\
\hline Ruptured ectopic & 3 & 4.0 \\
\hline Rupture uterus & 1 & 1.3 \\
\hline $\begin{array}{l}\text { Hypertensive disorders } \\
\text { of pregnancy }\end{array}$ & 17 & 22.6 \\
\hline HELLP & 5 & 10.7 \\
\hline Eclampsia & 8 & 10.7 \\
\hline Preeclampsia & 4 & 9.3 \\
\hline Sepsis & 5 & 6.7 \\
\hline Non-obstetric causes & 24 & 32.1 \\
\hline $\begin{array}{l}\text { Jaundice complicating } \\
\text { pregnancy }\end{array}$ & 7 & 9.3 \\
\hline Dengue & 4 & 5.3 \\
\hline Malaria & 2 & 2.7 \\
\hline Pneumonia & 2 & 2.7 \\
\hline Pyelonephritis & 1 & 1.3 \\
\hline DKA & 2 & 2.7 \\
\hline Bronchial asthma & 1 & 1.3 \\
\hline Cardiac failure & 1 & 1.3 \\
\hline PAH & 1 & 1.3 \\
\hline Peritonitis & 1 & 1.3 \\
\hline $\begin{array}{l}\text { PRES with tonsillar } \\
\text { herniation, obstructive } \\
\text { hydrocephalus }\end{array}$ & 1 & 1.3 \\
\hline TRALI & 1 & 1.3 \\
\hline \multicolumn{3}{|c|}{$\begin{array}{l}\text { *DKA-Diabetic ketoacidosis, PAH-Pulmonary artery } \\
\text { hypertension, PRES-Posterior reversible encephalopathy } \\
\text { syndrome, TRALI-Transfusion-related acute lung injury, PPH- } \\
\text { Postpartum Haemorrhage, APH- Antepartum Haemorrhage }\end{array}$} \\
\hline
\end{tabular}

Majority of were admitted for obstetric causes 51 (68\%), non-obstetric causes 24 (32\%). Major obstetric causes were obstetric haemorrhage 29 (39.6\%), hypertensive disorders of pregnancy $17(22.6 \%)$, sepsis $5(6.7 \%)$. Among the non-obstetric causes, jaundice complicating pregnancy was most common $7(9.3 \%)$ and dengue fever 4 (5.3) (Table 1).

Most common mode of termination of pregnancy was emergency LSCS 39 (52\%) followed by vaginal delivery $12(16 \%)$. Mechanical ventilation was needed in 44 $(58.7 \%)$ followed by inotropic support in 30 (40\%), haemodialysis in 8 (10.7). Transfusion of Blood and blood products was needed in $56(74.6 \%)$. More than five units of blood and blood products transfusion were required in $46.6 \%$ of patients. Mean packed red blood cells (PRBC) units transfused was $4.13 \pm 2.38$, fresh 
frozen plasma units (FFP) was $6.68 \pm 5.3$, platelet units transfused was $7.53 \pm 4$.

Table 2: Analysis of 12 cases of death.

\begin{tabular}{|lll|}
\hline Case No. & Diagnosis & Cause of death \\
\hline 1 & Chronic Hypertension & Cardiac failure \\
\hline 3 & PPH & Shock with DIC \\
\hline 4 & $\begin{array}{l}\text { Postoperative LSCS } \\
\text { with Sepsis }\end{array}$ & MODS \\
\hline 5 & Dengue shock syndrom & MODS \\
\hline 6 & Cardiac disease & Severe PAH \\
\hline 7 & $\begin{array}{l}\text { Post hysterotomy } \\
\text { with sepsis }\end{array}$ & MODS \\
\hline 8 & HELLP & MODS \\
\hline 9 & PPH & MODS \\
\hline 10 & PRES & Cardiorespiratory \\
\hline 11 & Severe pre-eclampsia & MODS \\
\hline 12 & Jaundice & MODS \\
\hline
\end{tabular}

MODS- Multiple Organ Dysfunction Syndrome

$44(58.6 \%)$ pregnancies had live birth, 14 (18.6\%) pregnancies ended up in IUFD, 9 (12\%) pregnancies needed induced abortion. Out of 44 live births $26(59 \%)$ were admitted to NICU.

Table 3: Causes of maternal death.

\begin{tabular}{|lll|}
\hline Cause of death & $\begin{array}{l}\text { Number of } \\
\text { patients }\end{array}$ & $\begin{array}{l}\text { Percentage } \\
(\%)\end{array}$ \\
\hline $\begin{array}{l}\text { Hypertensive disorders } \\
\text { of pregnancy }\end{array}$ & 4 & 33.3 \\
\hline Sepsis & 3 & 25 \\
\hline PPH & 2 & 16.6 \\
\hline Dengue shock syndrome & 1 & 8.3 \\
\hline $\begin{array}{l}\text { Cardiac disease } \\
\text { complicating pregnancy }\end{array}$ & 1 & 8.3 \\
\hline $\begin{array}{l}\text { Jaundice complicating } \\
\text { pregnancy }\end{array}$ & 1 & 8.3 \\
\hline \begin{tabular}{l} 
Total number of deaths \\
\hline
\end{tabular} & 12 & 100 \\
\hline
\end{tabular}

12 maternal deaths occurred during the study period. Most common cause of death in our study was MODS following complications of hypertensive disorders of pregnancy (Table 2). The Second most common cause of death was sepsis (Table 3 ).

\section{DISCUSSION}

Despite the drastic decrease in maternal morbidity over the last few decades because of improvements in obstetric care, maternal mortality remains to be a challenge in the developing world. Critically ill obstetric patients who need ICU admission constitute $1.29 \%$ of all the deliveries in our hospital, compared to $0.87 \%$ in the study by Saha $\mathrm{R}$ et al4 and $0.8 \%$ by Verma et al. ${ }^{5}$ The rate is comparable with other studies also (0.1-0.9\%). ${ }^{6}$ The slightly higher rate of ICU admission in our institution was explained by it being a tertiary referral centre. In developed countries, obstetric patients only account for a small proportion $(<2 \%)$ of ICU admissions, whereas the figure is up to $7 \%$ in India and the maternal mortality ratio also significantly higher in developing countries.7 Obstetric patients constitute $1.1 \%$ of total ICU admissions in the present study, which was less when compared to the study conducted in Nepal by Saha R et al, where obstetric patients constitute $4.32 \%$ of total ICU admissions. ${ }^{4}$ Most of the women admitted to the ICU were young (mean age $=24.1 \pm 4.4$ years), postpartum $(\mathrm{n}=55,73.3 \%)$. These results were similar to study by Verma et al, Saha et al, Chawla et al, Gupta et al, and Ramachandra Bhat et al. ${ }^{4,5,8-10}$

Table 4: Comparison of causes for ICU admission.

\begin{tabular}{|c|c|c|c|}
\hline Study & $\begin{array}{l}\text { Year of } \\
\text { publication }\end{array}$ & $\begin{array}{l}\text { Obstetric } \\
\text { haemorrhage }\end{array}$ & $\begin{array}{l}\text { Hypertensive } \\
\text { disorders }\end{array}$ \\
\hline $\begin{array}{l}\text { Present } \\
\text { study }\end{array}$ & & $38.6 \%$ & $22.6 \%$ \\
\hline $\begin{array}{l}\text { Gupta } \\
\text { et } \mathrm{al}^{9}\end{array}$ & 2016 & $62 \%$ & $16 \%$ \\
\hline $\begin{array}{l}\text { Ashraf } \\
\text { et al }\end{array}$ & 2014 & $51 \%$ & $20 \%$ \\
\hline $\begin{array}{l}\text { Verma } \\
\text { et } \mathrm{al}^{5}\end{array}$ & 2014 & $46 \%$ & $15 \%$ \\
\hline $\begin{array}{l}\text { Chawla } \\
\text { et } \mathrm{al}^{8}\end{array}$ & 2013 & $30 \%$ & $40 \%$ \\
\hline $\begin{array}{l}\text { Saha R } \\
\text { et } \mathrm{al}^{4}\end{array}$ & 2013 & $16 \%$ & $42 \%$ \\
\hline $\begin{array}{l}\text { Khan } \\
\text { et } \mathrm{al}^{17}\end{array}$ & 2012 & $38 \%$ & $16 \%$ \\
\hline
\end{tabular}

Table 5: Comparison of maternal mortality.

\begin{tabular}{|c|c|c|c|}
\hline Study & $\begin{array}{l}\text { Maternal } \\
\text { mortality } \\
(\%)\end{array}$ & $\begin{array}{l}\text { Cause of } \\
\text { death }\end{array}$ & $\begin{array}{l}\text { Disease } \\
\text { concerned }\end{array}$ \\
\hline Present study & y 16 & MODS & $\begin{array}{l}\text { Hypertensive } \\
\text { disorders } \\
\text { of pregnancy }\end{array}$ \\
\hline Verma et $\mathrm{al}^{5}$ & 19.1 & MODS & APH,PPH \\
\hline Ashraf et al ${ }^{12}$ & 13 & $\begin{array}{l}\text { MODS } \\
\text { WITH } \\
\text { DIC }\end{array}$ & PPH \\
\hline Saha $R$ et $\mathrm{al}^{4}$ & 6 & MODS & PPH \\
\hline Khan et al ${ }^{17}$ & 65 & MODS & PPH \\
\hline Chawla et al ${ }^{8}$ & 28.5 & DIC & $\begin{array}{l}\text { LIVER } \\
\text { FAILURE }\end{array}$ \\
\hline Gupta et $\mathrm{al}^{9}$ & 41.6 & MODS & PPH \\
\hline
\end{tabular}

Postpartum admissions of obstetric patients to ICU were significantly higher. This could be attributed to the hemodynamic changes in the postpartum period which show a $65 \%$ increase in cardiac output, acute blood loss during delivery and decrease in plasma oncotic 
pressure. ${ }^{11}$ Secondly, there is a general reluctance to move a pregnant woman away from the proficiency of obstetrician's care unless it is absolutely necessary. Of all the admissions, $6.7 \%$ were completely unbooked and not investigated during the whole antenatal period, $77 \%$ were registered/ booked at other hospitals, referred to our hospital because of complications and $16 \%$ were booked in our hospital. These results were comparable to study conducted by Ashraf et al, where $60 \%$ cases are referred cases. ${ }^{12}$ The majority of referred cases were from peripheral health centres and nursing homes which are poorly equipped to manage obstetric emergencies, in terms of blood components and ventilator support. Timely referral to a tertiary medical facility is an important predictor of the morbidity and mortality of patients admitted to ICU for further management and stabilization.

Most of the cases were primigravida's (54.7\%), similar to study by Chawla et al, (primis-68.5\%) but contrast to study by Verma et al, where the majority $(60.2 \%)$ were multigravida. ${ }^{5,8}$ Median gestational age for these critical patients at the time of hospital admission was 35 (29 - 37) weeks.

Majority of the cases admitted to ICU were terminated by emergency LSCS $(n=39,52 \%)$, shifted to ICU after delivery for the management of intraoperative and postoperative complications mainly $\mathrm{PPH}$. Present study showed 52\% LSCS, Ashraf et al (63.3\%), Saha R et al $(70 \%))^{4,12}$

It has been reported that the most common reasons for ICU admission of obstetric patients are hypertensive disorders and massive obstetric haemorrhage. It was emphasized that early detection and prompt referral to tertiary centres with intensive care facilities to provide optimum care of circulation, blood pressure and ventilation could minimize the prevalence of multiple organ failure and mortality in critically ill obstetric patients. ${ }^{13,14}$ In our study, obstetric causes were the significant causes of morbidity and ICU transfer (68\%), as compared to non-obstetric causes (32\%), in which medical disorders constituted $30.6 \%$ and surgical cause constituted $1.3 \%$. The major obstetric causes were obstetric haemorrhage $(n=29,38.6 \%)$, hypertensive disorders (severe preeclampsia, eclampsia, HELLP) $(n=17,22.6 \%)$ and sepsis $(n=5,6.7 \%)$.

Obstetric haemorrhage, hypertensive disorders were found to be the most common causes of ICU admission in various earlier studies also (Table 4).

Uterine atony was found to be the underlying cause of PPH in the majority of cases $(80 \%)$. Out of 16 cases of atonic PPH, 6 cases were treated with balloon tamponade, 2 cases were treated with B-Lynch haemostatic sutures. In 6 out of 16 cases of atonic PPH, peripartum hysterectomy was done to control massive haemorrhage. Mortality due to PPH was $9.5 \%$ (2 out of 12 cases). There is a dire need for advanced technology even in our tertiary hospitals. The use of arterial embolization is found to be an effective alternative to caesarean hysterectomy in managing the cases of PPH in advanced setups. ${ }^{15}$ Among medical disorders, jaundice complicating pregnancy was the most common cause responsible for ICU admission $(n=7,9.3 \%$ of all ICU admissions). Infections also played an important role. Dengue fever and associated complications were responsible for $5.3 \%$ of all ICU admissions. Other medical diseases include malaria, pneumonia, pyelonephritis, DKA, bronchial asthma, cardiac failure, PAH, TRALI. Only one case was admitted for peritonitis following caesarean section, where exploratory laparotomy was done and the patient was salvaged. In contrast to this, according to the study conducted by Saha $\mathrm{R}$ et al, Verma et al, cardiac diseases was the most common medical cause for ICU admission. ${ }^{4,5}$ This difference was due to the fact that, all cardiac patients who are sick were admitted to Coronary care unit (CCU) rather than general ICU in our hospital.

The mean length of ICU stay was $4.1 \pm 2.7$ days which is similar to most of the studies indicating that most of the patients did not have a major complication during their ICU admission. 2,6,16 The minimum duration of ICU stay was 1 day and maximum was 33 days.

When primary indications for ICU admission were analysed, hemodynamic instability and respiratory insufficiency were major causes. In our study, mechanical ventilation was the most common intervention done in ICU $(n=44,58.7 \%)$. One patient required 23 days of ventilator support to survive. Extracorporeal membrane oxygenation (ECMO) was used in one patient of ARDS, but failed to revive the patient. Inotropes were used in $40 \%$ of patients for treating hemodynamic instability. These results were similar to studies by Verma et al, Gupta et al, Ashraf et al. ${ }^{5,9,12}$ CVP monitoring was done in $38.6 \%$ of patients and arterial line insertion was done in $34.7 \%$ of patients.

In the present study, $74.6 \%$ of patients needed transfusion of blood and blood products. More than five units of blood and blood products transfusion were required in $46.6 \%$ of patients, indicating that blood loss and hemodynamic instability due to obstetric haemorrhage was the major cause of admission to ICU. The requirement of transfusion of more than 5 units of blood and blood products was significantly higher $(64.12 \%)$ in a large study conducted in northern India in 2011 by Verma et al. ${ }^{5}$ In a patient who was a case of MODS with DIC with sepsis following LSCS, a total number of 52 units of blood and blood products were transfused (15 units of packed red blood cells, 15 units of fresh frozen plasma, 15 units of random donor platelets, 4 units of single donor platelets, 3 units of cryoprecipitate). In our study, need for dialysis was $9.3 \%$ of obstetric patients admitted to ICU, comparable to $10 \%$ of patients in the study by Khan et al, and more compared to study by Saha 
$\mathrm{R}$ et al (4\%) and Ashraf et al (5.45\%). ${ }^{4,12,17}$ One patient, who was a case of acute renal failure following primary emergency LSCS, required dialysis for 22 times before getting discharged from the hospital. The most common indication for dialysis in our study was acute kidney injury from complications of HELLP syndrome.

Magnesium sulphate was used in $18.7 \%$ of patients admitted mainly for treatment of eclampsia which was less compared to study by Saha R et al (30\%) and more compared to study by Khan et al $(10 \%){ }^{4,17}$ The difference was due to the varied incidence of severe preeclampsia and eclampsia in different studies. The incidence of maternal mortality has significantly decreased in the developed countries $(0 \%$ by Lapinsky et al, $2.3 \%$ by Mahutte et al, $11 \%$ by Vasquez et al) as compared to the developing countries $(41.67 \%$ by Togal et al, $33.81 \%$ by Gilbert et al) in recent years. ${ }^{18-22}$ Increased maternal mortality ratio in developing countries have been attributed to treatment by quacks, low socioeconomic status, poor antenatal care, low haemoglobin levels and poor nutritional status in obstetric patients. ${ }^{9}$ The maternal mortality in our study was $16 \%$, which was comparable to study conducted by Verma et al (19.1\%), Ashraf et al (13\%) but less compared to study by Khan et al (65\%), Chawla et al (28\%), Gupta et al $(41.6 \%) .^{5,8,9,12,17}$ Most common cause of death in our study was MODS following complications of hypertensive disorders of pregnancy, whereas in various studies, the major cause of death was PPH (Table 5).

The incidence of live births was $58.6 \%$, which was comparable to study by Khan et al, where the live birth rate was found to be $40.5 \%$, but less when compared to the study by Verma et al, where the live birth rate was $83.5 \% .^{5,17}$ Foetal mortality rate that is a combination of IUFD and stillbirth rate was found to be $24 \%$ in our study, which was similar to study by Gombaret al, where foetal mortality rate was $21.1 \% .^{23}$ Out of total live births, APGAR score was less than 7 for $42 \%$ of babies at 1 minute and less than 7 for $32 \%$ of babies at 5 minute. Out of total live births, $59 \%$ were admitted to NICU.

\section{CONCLUSION}

The findings of the present study reinforce the statement by WHO that "There is a story behind every maternal death or life-threatening complication. Understanding the lessons to be learned can help to avoid such outcomes". Low socioeconomic status, lack of education and poor antenatal care, late referral of high-risk cases have been found to have a considerable effect on obstetric complications and outcome. Awareness should be created among the population regarding the importance of adequate antenatal care, detection of the danger signs of various obstetric complications and need for contacting the medical facility at the earliest in a case of emergency situations. Early detection and prompt referral to the tertiary centre with intensive care facilities should be promoted among the medical fraternity to reduce the incidence of ICU admissions, maternal mortality and morbidity.

Optimum care of circulation, blood pressure, and ventilation could minimize the prevalence of multiple organ failure and mortality in critically ill obstetric patients admitted to ICU.

To achieve all of these, a multidisciplinary team approach is required in ICU. All residents of obstetrics and gynaecology should have short mandatory training phase in critical care.

Multi-centric prospective studies in this regard are required to further validate the findings of our study and also provide more authenticated data for formulating evidence-based national guidelines.

\section{ACKNOWLEDGMENTS}

Authors would like to thanks to Department of Obstetrics and Gynecology and ICU of NRI Medical College and General Hospital for allowing us to conduct this study. Authors extend his acknowledgement to all the women who were included in this study.

Funding: No funding sources Conflict of interest: None declared

Ethical approval: The study was approved by the Institutional Ethics Committee

\section{REFERENCES}

1. Pollock W, Rose L, Dennis C-L. Pregnant and postpartum admissions to the intensive care unit: a systematic review. Intensive Care Med. 2010;36(9):1465-74.

2. Richa F, Karim N, Yazbeck P. Obstetric admissions to the intensive care unit: an eight-year review. J Med Liban. 2008;56(4):215-9.

3. Making pregnancy safer WHO Regional Office for Europe, 2013. Available at http://www.euro.who.int/pregnancy.

4. Saha R, Shakya A. Study of obstetric patients admitted to intensive care unit at Kathmandu Medical College Teaching Hospital. Jounal of Kathmandu medical college. 2013;2(4):196-200.

5. Verma D, Rathore AM. Obstetric admissions to the intensive care unit of a tertiary hospital in northern India. Int J Biomed Res. 2014;5(9):539-42.

6. Zwart JJ, Dupuis JRO, Richters A, Ory F, van Roosmalen J. Obstetric intensive care unit admission: a 2-year nationwide population-based cohort study. Intensive Care Med. 2010;36(2):25663.

7. Karnad DR, Lapsia V, Krishnan A, Salvi VS. Prognostic factors in obstetric patients admitted to an Indian intensive care unit. Crit Care Med. 2004;32(6):1294-9. 
8. Chawla S, Nakra M, Mohan S, Nambiar BC, Agarwal R, Marwaha A. Why do obstetric patients go to the ICU? A 3-year-study. Med J Armed Forces India. 2013;69(2):134-7.

9. Gupta S, Naithani U, Doshi V, Bhargava V, Vijay BS. Obstetric critical care: A prospective analysis of clinical characteristics, predictability, and fetomaternal outcome in a new dedicated obstetric intensive care unit. Indian $\mathbf{J}$ Anaesth. 2011;55(2):146-53.

10. Ramachandra Bhat PB, Navada MH, Rao SV, Nagarathna G. Evaluation of obstetric admissions to intensive care unit of a tertiary referral center in coastal India. Indian J Crit Care Med Peer-Rev Off Publ Indian Soc Crit Care Med. 2013;17(1):34-7.

11. Ashraf N, Mishra SK, Kundra $P$, Veena $P$, Soundaraghavan S, Habeebullah S. Obstetric Patients Requiring Intensive Care: A One Year Retrospective Study in a Tertiary Care Institute in India. Anesthesiol Res Pract. 2014;2014:e789450.

12. Zeeman GG. Obstetric critical care: a blueprint for improved outcomes. Crit Care Med. 2006;34(9 Suppl):S208-214.

13. Price LC, Germain S, Wyncoll D, Nelson Piercy C. Management of the critically ill obstetric patient. Obs Gynae Reprod Med. 2009;19:350-8.

14. Natali YWL, Arther CWL, Keeny KCC, Yan WW. Clinical characteristics and outcomes of obstetric patients admitted to Intensive Care Unit: a 10 year retrospective review. Honkong Med J. 2010;16:1825.

15. Faponle AF, Adenekan AT. Obstetric admission into the Intensive Care Unit in Suburban University Teaching Hospital. Nep J Obstet Gynaecol. 2012;6(2):33-6.
16. Sadia Khan. An analysis of critically ill obstetric patients admitted to intensive care unit of a tertiary care centre. J Soc Obstet Gynaecol Paksitan. 2012;2(1):37-44.

17. Lapinsky SE, Kruczynski K, Seaward GR, Farine D, Grossman RF. Critical care management of the obstetric patient. Can J Anaesth J Can Anesth. 1997;44(3):325-9.

18. Mahutte NG, Murphy-Kaulbeck L, Le Q, Solomon J, Benjamin A, Boyd ME. Obstetric admissions to the intensive care unit. Obstet Gynecol. 1999;94(2):2636.

19. Vasquez DN, Estenssoro E, Canales HS, Reina R, Saenz MG, Das Neves AV, et al. Clinical characteristics and outcomes of obstetric patients requiring ICU admission. Chest. 2007;131(3):71824.

20. Togal T, Yucel N, Gedik E, Gulhas N, Toprak HI, Ersoy MO. Obstetric admissions to the intensive care unit in a tertiary referral hospital. J Crit Care. 2010;25(4):628-33.

21. Gilbert TT, Smulian JC, Martin AA, Ananth CV, Scorza W, Scardella AT, et al. Obstetric admissions to the intensive care unit: outcomes and severity of illness. Obstet Gynecol. 2003;102(5):897-903.

22. Gombar S, Ahuja V, Jafra A. A retrospective analysis of obstetric patient's outcome in intensive care unit of a tertiary care center. J Anaesthesiol Clin Pharmacol. 2014;30(4):502-7.

Cite this article as: Bahadur BR, Kodey $\mathrm{P}$, Tanniru J, Tirumala S. Study of outcome of obstetric emergencies admitted to intensive care unit. Int $\mathbf{J}$ Reprod Contracept Obstet Gynecol 2018;7:2909-14. 